\title{
Miguel de Unamuno y Santiago Alba
}

\author{
José Maria Marin Arce
}

\section{TRAS EL DESASTRE DEL 98}

A partir de la correspondencia privada entre Unamuno y Alba, reconstruimos las relaciones que durante más de treinta años tuvieron el que fuera rector de la Univerdad de Salamanca, figura destacada de la "generación del 98 ", y el político zamorano, numerosas veces ministro y jefe de la izquierda liberal.

Unamuno, nacido en Bilbao en 1864, hijo y nieto de comerciantes vascos y de familia liberal, a los dieciséis años se traslada a Madrid para estudiar Filosofía y Letras. En 1891 gana las oposiciones a la cátedra de lengua griega en la Universidad de Salamanca, convirtiéndose, además, durante la década de los 90 , en un prestigioso articulista cuyos comentarios políticos pesan extraordinariamente en la opinión pública.

Alba nació en Zamora en 1872 y a los quince años viajó a Valladolid donde ingresó en la Facultad de Derecho, terminando su licenciatura en 1892 y el doctorado tres años más tarde, esta vez en la Universidad de Madrid. Muy pronto, el joven Alba se vio inclinado al mundo del periodismo y de la política. Comenzó colaborando en diarios locales como La Lealtad y la Opinión para, poco más tarde, en 1893, comprar el Norte de Castilla, diario vallisoletano que, dirigido por Silió, se convirtió rápidamente en uno de los periodicos liberales más representativos de Castilla .

Enseguida Alba despertó a la acción política formando parte del grupo de Germán Gamazo y en 1897, sin tener la edad reglamentaria, fue ele-

\footnotetext{
1 Alba congregó en torno al Norte de Castilla a numerosas personalidades políticas e intelectuales de muy diversas ideologias. Prestaron su pluma al diario castellano, entre otros, Zorrilla, Núñez de Arce, Emilia Pardo Bazán, Ramiro de Maeztu, Macias Picavea, Royo Villanova, Federico Santander, Francisco de Cossio... y, como no, Unamuno.
} 
gido concejal liberal en Valladolid con un amplio respaldo popular y con el apoyo de las clases mercantiles, agrupadas en la Cámara de Comercio de la que Alba era secretario. Desde su cargo en el Ayuntamiento, anticipándose a la gran labor hacendistica que realizó años más tarde, preparó un proyecto presupuestario dirigido a reorganizar el sistema financiero y a fortalecer la Hacienda municipal con una progresista reforma impositiva; obra que recuerda, según Garcia Veneno, los ensayos y trabajos municipales realizados en la Europa central por los ediles socialistas y que tan desconocida era en nuestro pais ${ }^{2}$.

A principios de 1899, Alba traduce y prologa el libro del sociólogo francés Edmundo Demolins titulado: «En qué consiste la superioridad de los anglosajones" " ${ }^{3}$. En el extenso prólogo - 133 páginas - Alba descubre su pensamiento politico, profundamente liberal, reaccionando contra los males de España -en el más puro estilo regeneracionista-, contra el sistema económico y educativo imperante y contra el régimen político y los políticos que tenian la responsabilidad del Poder desde 1876. Con el recuerdo vivo del desastre del 98, Alba, con mentalidad joven y esperanzada, renuncia sin tristeza a unas colonias "en las que no logramos ser ni explotadores ni queridos" y que tenían subyugadas a la economia española con un absurdo proteccionismo arancelario. Otra de las grandes preocupaciones que manifiesta en su prólogo es la catastrófica situación de la enseñanza, abogando por la dignificación del Magisterio y de la escuela pública y por el aumento del presupuesto de Instrucción, durante estos años el más bajo de Europa. Aborda, también, los problemas del sistema político de la Restauración, reconociendo la conveniencia del parlamentarismo pero sin dejar por eso de criticar sus defectos: "el clásico pucherazo o el encasillado, g!orioso invento nacional'. La democratización de la politica, la mayor representación del Parlamento y la participación en la vida pública de las clases medias y del recién nacido partido socialista eran aspectos esenciales que Alba - en su prólogo- defendía y que en el futuro determinarán su acción política y el programa de la izquierda liberal.

En febrero de 1899, Alba envia este prólogo a Unamuno, "su amigo, honrado, original, culto y sincero", de quien espera una critica dura, sin retóricas ni falsas admiraciones que no harian otra cosa que degenerarla y desvanecerla ${ }^{4}$.

'Garcla Venero, M., Santiago Alba. Monárquico de razón. Madrid, Aguilar, 1963, pág. 22.

${ }^{3}$ Demolins era discipulo del economista Le Play, director de la revista La Science Sociale y fundador de /'Ecole des Roches, experimento reformador de los métodos educativos franceses.

4 Archivo Unamuno. Carta de Alba a Unamuno, febrero 1899. 
Inmediatamente, Unamuno le escribe una extensa carta en la que analiza pormenorizadamente el libro de Demolins y el prólogo de Alba. Coincide con el joven político liberal en su diagnóstico sobre la enseñanza, en la falta de democracia y en la necesidad de una mayor colaboración con el partido socialista. Sin embargo, no se muestra tan crítico en los supuestos males de España, pues «aún reconociendo - le dice a Albaque el cuadro que usted ha trazado es exacto, claro y vivo, yo no estimo que estemos tan mal. La riqueza pública aumenta y la honda vida nacional sigue su curso tranquilo, y lento, pero seguro" ${ }^{5}$. En 1899, Unamuno ha abandonado la militancia socialista y gran parte de su radicalismo, anunciándose ya su preocupación religiosa y su falta de interés por la política. Es sintomático de esta evolución la diferencia entre la violenta critica que Unamuno hace del sistema electoral en 1897, al que acusa de corrupto y falso, y la "cuasi» justificación del caciquismo y la oligarquia que realiza, en 1901, en la contestación a la encuesta promovida por Joaquín Costa ${ }^{6}$.

A los «hombres de 98", fuertemente impactados por el desastre colonial, les une la necesidad de una revisión de los valores caducos y de la ideologia dominante que sustenta al régimen de la Restauración; también les aglutina la idea de repensar España y la forma de abrirse a Europa. Unamuno, en referencia al libro de Demolins, confiesa a Alba que es imprescindible «abrir lo más posible las fronteras, no para que nos invada y anule lo de fuera, sino para que a su contacto, despierte lo hondo nuestro». Sin despreciar el aperturismo, Unamuno busca en la tradición histórica de nuestro pais los verdaderos valores sobre los que cimentar el futuro de España y acuña el concepto de intra-historia como lo de permanente que hay cen la vida silenciosa de los millones de hombres...que van a sus campos a proseguir la oscura y silenciosa labor cotidiana y eterna...que es la sustancia del progreso, la tradición, la tradición eterna, no la tradición mentida que se suele ir a buscar al pasado enterrado en libros y papeles y monumentos y piedras" ${ }^{7}$.

No cree Unamuno en la pretendida superioridad de los anglosajones, "porque no me parece superioridad -escribe a Alba- la de dominar más territorio, sino la de saber aprovechar la vida». El único dominio real

\footnotetext{
Archivo Alba. Carta de Unamuno a Alba, 28-2-1899.

"Unamuno, M., “El socialismo en España” (Der sozialismus in Spanien), en rev. Der Sozialistiche Akademiken. Berlin 9-9-1897, en Obras Completas, tomo IX. Madrid, Escelier, 1966, págs. 735-741. Oligarquia y caciquismo como forma actual de gobierno de España, urgencia y modo de cambiarla. Encuesta recogida por Joaquín Costa. Madrid 1902, págs. 487-493.
}

' Unamuno, M., En torno al casticismo. Madrid, Alianza Editorial, 1986, págs. 33-34. 
que admite proviene de la lengua inglesa, hablada a fines de siglo por más de 100 millones de personas y la más difundida, "the english-speaking folk" que con tanto orgullo pregonan los ingleses. Si para Unamuno el inglés es la lengua más adelantada, la que más precisión tiene de las lenguas latinas, la fecundidad y el poder de derivación de la germánicas y una enorme agresividad, sin embargo, a un experto filólogo como él, no se le escapa el peligro que acecha a una lengua tan flexiva y análitica de llegar a convertirse en un "monosilabo chinesco" altamente simbólico ${ }^{8}$.

El rechazo a la soberbia inglesa no impide a Unamuno reconocerse entusiasta de Inglaterra y del genio inglés, pero «no del inglés industrial - como refiere a Alba - sino del inglés walterscotiano, del pueblo que culmina en un dulcisimo Wordsworth, en un Coleridge, en un Shelley, en un Carlyle (al que tiene como maestro)"; tampoco acepta a la Inglaterra imperialista, tan bien representada por Cecilio Rhodes. Parecidos juicios vierte sobre Alemania, "a la que admiro y siento cariño, a la vieja, a la romántica, a la del claro de luna transcendental, a la de Voss, Klopstock, Goethe, Schiller, Uhland, Senan, etc., no a la de los junker prusianos y del bárbaro militarismo. Bismark - dice- me es odioso".

En numerosos artículos publicados, entre 1894 y 1897, en La lucha de clases, semanario socialista de Bilbao, Unamuno se manifiesta contra la guerra y contra toda forma de imperialismo. Para él, el mayor obstáculo a la verdadera e intima libertad de los pueblos y a la libertad económica es el militarismo. La supremacia de los pueblos y la exaltación de las virtudes militares que subyacen en la "bestial filosofia de Moltke", conducen al racismo, a la barbarie y a la esclavitud. También hay profundas razones económicas que convierten a la guerra en un suculento negocio; a propósito de ello, Unamuno denuncia a los "yankees" como instigadores y protectores de la insurreción cubana para defender los intereses del sindicato del azúcar, el "Sugar-trust" ${ }^{9}$.

Unamuno critica a Demolins su manifiesto antisocialismo, pues piensa que "es un error - le escribe a Alba- el creer que el socialismo pretende imponer la omnipotencia del Estado, tal como hoy entendemos a éste. $Y$ decir que no hay socialismo en Inglaterra, el pais clásico de la legislación del trabajo y la intervención del Estado y de la Ley en las relaciones entre obreros y patronos, es ya un exceso. Su germanofobia y su

"Unamuno, M., "The english-speaking folk", en La vida literaria, 11-3-1899.

9 UnAmuno, M., "El militarismo", "Un mal inevitable», "La guerra es un negocio" y "El negocio de la guerra", en La lucha de clases. Bilbao, 31-3-1895, 19-10-1895, 26-10-1895 y 9 5-1896. «Paz y trabajo» en El Socialista, 1-5-1896. 
ciega hostilidad al socialismo le pierden a Demolins. Y le perjudica su espíritu científico sectario dentro de la esencia de Le Play». Unamuno ingresó en el partido socialista (agrupación de Bilbao) en 1894 y permaneció en él hasta principios de 1897. Durante este breve periodo, colaboró muy activamente en varias publicaciones socialistas españolas y europeas ${ }^{10}$, en las que expuso su muy particular concepción del socialismo. Aunque parezca contradictorio, llega al socialismo no sólo de la mano de Marx sino, esencialmente, a través de los clásicos de la economía liberal, Adam Smith, Stuart Mill, Ricardo, Malthus, etc., los economistas de la Escuela de Manchester y sus más contemporáneos, Spencer, Carlyle o Ruskin. La antinomia entre el socialismo y liberalismo no existe para Unamuno, más al contrario el socialismo sólo es entendible para él como una profundización del liberalismo. Esta visión le conduce a exaltar el más puro librecambismo, rechazar, por tanto, el proteccionismo y abjurar del socialismo de Estado, del que dice: «es autoritario e impositivo, es cosa muy distinta y, en mi sentir, opuesto al socialismo internacional, popular y democrático" ". La critica al proteccionismo y al socialismo dogmático es muy semejante a la que, desde la óptica liberal, desarrolla Alba ${ }^{12}$.

El progesivo alejamiento de Unamuno del partido socialista comienza con la falta de fe en la lucha de clases, para muy pronto evolucionar del simple economicismo a una concepción casi religiosa del socialismo y a la defensa de la individualidad, que no del individualismo, como verdadera aspiración social. Es el anuncio de su posterior acercamiento al cristianismo de raiz luterana ${ }^{13} \mathrm{y}$ al abandono de su militancia socialista, que no le conduce a una brusca ruptura con el partido, es más, continúa colaborando con diversas publicaciones socialistas, sobre todo con La LUcha de clases para quien escribe todos los años un artículo conmemorativo del Primero de Mayo.

Si en los pocos años de fervor socialista, Unamuno defiende con entusiasmo el liberalismo, más consecuentemente lo hará ahora, en 1899 , cuando ya ha roto las fidelidades que le unían al partido. La afinidad ideo-

\footnotetext{
${ }^{10}$ Unamuno fue colaborador asiduo de la revista La lucha de clases de Bilbao. También escribió en otras publicaciones socialistas como El Socialista, La Revista socialista, La Nueva Era, La Ilustración del pueblo y Der Sozialistiche Akademiken de Berlín.

"Unamuno, M., "Proteccionismo y socialismo", en La lucha de clases , 3-3-1895.

12 ALBA, S., El problema arancelario cubano y la producción castellana, conferencia pronunciada en el círculo de la Unión Mercantil e Industrial de Valladolid el 27-3-1897. Valladolid, Imprenta castellana, 1897.

${ }^{13}$ Sobre la cercania de Unamuno al protestantismo son interesantes los comentarios de Pedro Badanelli en el libro 13 cartas inéditas de Miguel de Unamuno a Alberto Nin Rias, escritor uruguayo. Buenos Aires, edt. La Mandrágora, 1962.
} 
lógica que habia sentido en 1896 con el liberal italiano Francesco Nitti ${ }^{14}$, ahora se traducirá en una coincidencia plena con Alba. Ambos, Nitti y Alba, representantes del ala izquierda del partido liberal, estarán estrechamente ligados no sólo por vínculos de amistad sino por planteamientos políticos e ideológicos muy semejantes. Buena prueba de ello será la politica económica desarrollada por Nitti desde la presidencia del Gobierno italiano y por Alba desde el Ministerio de Hacienda y su mutuo interés en romper el angosto marco politico del régimen liberal, tanto en Italia como en España, abriéndolo hacia la izquierda socialista para facilitar el tránsito hacia la democracia.

\section{EN LOS AÑOS DE LA GUERRA EUROPEA}

Desde 1900, en que es nombrado Rector de la Universidad de Salamanca, Unamuno se va apartando progresivamente de la actividad politica y se dedica por entero a la labor docente. En esto años colabora asiduamente en La Nación de Buenos Aires y escribe Amor y Pedagogia (1902), Vida de Don Quijote y Sancho (1905), Por tierras de Portugal y España (1911), Del sentimiento trágico de la vida, Niebla (1914), etc. En agosto de 1914 su destitución como Rector le afecta extraordinariamente $y$, a partir de este momento, se entrega de lleno a la vida politica. En noviembre de 1915 se presenta candidato a concejal del Ayuntamiento salmantino, participa muy activamente en cuantas campañas aliadófilas se preparan y en politica nacional se alinea con los más críticos al sistema del turno ${ }^{15}$, al mismo tiempo que apoya los proyectos reformistas del albismo.

Al comienzo de la Gran Guerra, Alba, varias veces ministro y jefe de una de las facciones del liberalismo, se ha convertido en uno de los políticos más importantes de la Restauración. A principios de diciembre de 1915, Romanones forma Gobierno con la plena colaboración del resto de los liberales encabezados por Alba y Garcia Prieto. El Gabinete recién creado, del que eran ministros prestigiosas figuras del liberalismo, según su Presidente «la crema de liberales y demócratas» ${ }^{16}$, tuvo una larga duración —de diciembre de 1915 a abril de 1917- y una gran estabilidad,

\footnotetext{
${ }^{14}$ Unamuno, M., "Ceguera industrialista", en La lucha de clases, 30-5-1986.

"Unamuno, M., "Los profesionales de la política", en Nuevo Mundo. Buenos Aires, 9-71914.

${ }^{16}$ Romanones, Conde de, "Notas de una vida", en Obras Completas, tomo III, pág. 346.
} 
teniendo en cuenta la dificultad de aunar los intereses de las distintas familias liberales, los conflictos laborales surgidos en julio de 1916, las complicaciones en politica exterior derivadas del bloqueo y torpedeamiento de buques españoles por Alemania y los avatares por los que pasaron los proyectos fiscales y económico-financieros impulsados desde el Ministerio de Hacienda ${ }^{17}$.

El verdadero protagonista del Gobierno seria Santiago Alba. Primero en Gobernación y luego en Hacienda, sus iniciativas y actividades presidirán la vida del Gabinete y, además, marcarán el futuro inmediato del partido liberal. Alba, como ministro de la Gobernación y, por lo tanto, encargado de organizar las elecciones de abril de 1916, dirigió sus esfuerzos primero a impedir que la Lliga intentara copar las actas de diputados, como ya lo hizo con Solidaridad catalana en 1907, y segundo a conseguir el mayor acuerdo con los distintos grupos liberales y conservadores.

Como en ocasiones anteriores, estas elecciones no estuvieron libres de los tradicionales vicios del sistema -el encasillado, la compra de votos, el fraude electoral... - pero si se celebraron en un clima de cierta tranquilidad, pues Alba hizo lo posible en buscar el pacto entre los partidos dinásticos, evitando la violencia que habia caracterizado los anteriores comicios.

Sobre el caciquismo electoral y el comportamiento del ministro de la Gobernación en las elecciones tiene lugar una interesante polémica entre Unamuno y Alba. Se inicia el debate con un artículo del primero, en El Liberal, en el que pone en tela de juicio la limpieza de las elecciones y acusa a los políticos castellanos de caciquismo.

«Se acercan las elecciones generales -escribe Unamuno- y todo su triste cortejo de encasillamiento de gobernadores, y hasta de ministros, apernadores, de amenazas, halagos, cambalaches, de trueques, de esos que llaman sacrificios, de pordioseos y luego, como secuela y postre, de compensaciones y pequeñas vengazas vergonzosas, de toda la marrullera tramoya de nuestra nauseabunda técnica electoral.

Los partidos políticos dinásticos han caido en España en el más vergonzoso fulanismo. El que recorra las yermas soledades espirituales de esta triste Castilla, vivero de mendigos de todas clases, encontrará en

\footnotetext{
1 Marin ARCE, José Maria, Santiago Alba y la crisis de la Restauración. Madrid, UNED. 1990, págs. 38-61. «Antecedentes a la intervención de Estados Unidos en la Guerra Europea desde la perspectiva de la diplomacia española”, en rev. Espacio, Tiempo y Forma. Madrid, UNED, 1989, págs. 57-68.
} 
sus ciudades, villas y villorrios, organizadas las pandillas de lopecistas, gomecistas, perecistas, fernandistas, martinecistas, etc." ${ }^{18}$.

Alba contesta a Unamuno recriminándole «la cruel injusticia que encierra para Castilla sus palabras", su actitud pesimista ante la vida política, su falta de compromiso en la acción política y su desprecio indiscriminado hacia los políticos que, de hecho, pueden servir a otros como justificación a soluciones autoritarias. Contra esto Alba le previene como anticipándose a los tristes sucesos que para ambos tendrá, años más tarde, la Dictadura de Primo de Rivera.

"Sí es cierto que el cuerpo español necesita un "cirujano de hierro" -escribe Alba a Unamuno-, la obra de éste no conduciria sino a nuestra invalidez definitiva, de no ser completada por la de un uhábil ortopédico» que, por los procedimientos modernos, supliese, hasta donde los medios artificiales permitan, los organos y miembros amputados para entrar la grangrena, y que, en ocasiones, acertara a hacer innecesaria la intervención quirúrgica. $Y$ esa debe ser la doble aspiración del politico que tenga conciencia de su cometido, y de los que, sin querer llamarse politicos, ya sea por rigidez de principios, ya por mantener una postura que consideran gallarda, hacen, mal que les pese, "politica", en el sentido de influir con sus predicciones en la gobernación de los pueblos.

...respecto a las elecciones a que usted alude, puedo asegurarle $-y$ soy testigo y actor de mayor excepción- que existe un progreso extraordinario en las costumbres $y$ en los procedimientos y que las porquerias $y$ arbitrariedades de otros tiempos no se cometerán en éstas que yo voy a dirigir o, por lo menos, no pasarán sin la sanción que yo pueda imponerles" ${ }^{19}$.

No era lógico ni posible que Alba, a pesar de defender la reforma del sistema electoral y propugnar la transición hacia un régimen democrático, pudiera de un plumazo acabar con las perversiones del caciquismo. Asi termina reconociéndolo Unamuno que admite la buena voluntad de Alba al frente del Ministerio de Gobernación, y hace suyas las críticas de su amigo, poniendo fin a sus años de ostracismo político y proclamando su voluntad de hacer politica, política liberal, aunque no sea parlamentario.

«En su carta -escribe Unamuno a Alba- defiende usted a Castilla de mis ataques viniéndome a decir que las cosas van cambiando en ella. No cabe negarlo, en efecto, más no tan deprisa como hace falta.

\footnotetext{
18 Unamuno, M., «La lógica de la derrota», en El Liberal, 19-1-1916.

${ }^{19}$ Archivo Unamuno. Carta de Alba a Unamuno, 28-1-1916.
} 
Le digo que es posible que usted tenga razón en parte y que yo por vivir en Castilla y tocar sus males los siento vivamente... Mientras yo hacia, con otros pocos, una campaña agraria, estos sedicentes liberales estaban organizando comités electorales. Porque yo he hecho y hago política y política liberai y no merezco que se me cuente entre los abstencionistas. Me habla usted de los que sin querer llamarse "politicos", ya sea por ridigez de principios, ya sea por mantener una postura que consideran gallarda, hacen, mal que les pese, "política"... Recojo la alusión y le digo que si, que hago politica, y sin que me pese. $Y$ la habria hecho en el Parlamento... si no hubiese incompatibilidad entre ser rector y candidato ${ }^{20}$

A los pocos meses, en abril de 1916. Alba abandona la Cartera de Gobernación y pasa a ocuparse de la de Hacienda. Desde ese Ministerio prepara una serie de proyectos económico-financieros destinados a modernizar el aparato productivo español e intenta una profunda reforma fiscal a través de un proyecto de ley estableciendo un impuesto sobre los beneficios extraordinarios ocasionados por la guerra. Contra este proyecto se alzaron los grupos patronales más lucrados por las pingües ganacias que el conflicto les proporcionaba, encabezados por los políticos regionalistas catalanes y vascos y con el apoyo incondicional de las clases conservadoras. Sin embargo, otros muchos respaldaron la labor de Alba, entre ellos, por supuesto, Unamuno que ensalzó con entusiasmo sus proyectos, sin dudar ya de sus propósitos reformadores.

"He de hacer público - escribia Unamuno a Alba - mi parecer sobre sus proyectos. Lo considero una obligación. Que no se diga que soy de los que no saben más que censurar y deprimir y luego cada cual por su camino...

Siento ahora la «imperiosa obligación moral» de felicitarle y muy efusivamente, por esos proyectos. Bien, muy bien, pero muy bien. Ya era hora que se le empezase a dar contenido doctrinal a ese anémico y desvencijado partido liberal que iba reduciéndose a una mera cooperativa electorera. A mi satisfacción como ciudadano español y como liberal de buena ley, se une el ver que trata ustede de llevar a la práctica principios y orientaciones por los que, con otros, he peleado públicamente, con la pluma y con la lengua, en articulos, en meetings y en una campaña agraria. Ese es el camino; ese y no otro" ${ }^{21}$.

Frente a la dura oposición a los proyectos hacendisticos, Alba tuvo también numerosos, aunque insuficientes, apoyos. Gran cantidad de or-

20 Archivo Alba. Carta de Unamuno a Alba, 1-2-1916.

${ }^{21}$ Archivo Alba. Carta de Unamuno a Alba, 6-10-1916. 
ganizaciones sindicales agrarias, sociedades obreras, Ayuntamientos e incluso agrupaciones patronales, brindaron su amparo al ministro de $\mathrm{Ha}$ cienda, como también lo hizo la prensa, salvo excepciones, y la minoria republicano-socialista y los reformistas, en el Parlamento. Sin embargo, el Gobierno liberal y su grupo parlamentario, mayoritario en las Cámaras, que eran los llamados a defender las reformas hacendisticas, no les prestaron el auxilio necesario. No es extraño, por lo tanto, que Alba agradeciera la comprensión y el respaldo que Unamuno le brindaba, contestándole a su carta que «tanto como me duelen sus censuras me agrada su aplauso, al que da mayor valor de sinceridad la ruda franqueza y aún la acritud que usted suele poner en aquellos", asi como la ayuda en "esta durísima lucha contra las barricadas ...que convierten en carrera de obstáculos la marcha de mis proyectos. Si yo no tuviese fe ciega en que la realización de mis planes ha de contribuir al anhelado resurgimiento nacional me harian dudar las argucias, sofismas y hasta amenazas de fieros males con que combaten mi obra. Yo celebro que usted -termina la misiva- halle en mis planes un contenido doctrinal para el programa que debemos defender los liberales. En procurar sus realización hemos de empeñarnos los que aspiramos a ese nombre ${ }^{22}$.

La correspondencia entre ambos durante los años 1917 y 1918 demuestra que las reticencias de Unamuno han desaparecido $y$, ahora, todo se vuelven alabanzas al quehacer político de Alba, de quién proclama ser un ferviente seguidor. "Espero con impaciencia - le escribe a Alba a principios de 1917- a que las Cortes reanuden sus tareas para ver cómo se desarrollan sus planes financieros-politicos, sobre todo en lo que hace a los ingresos y nuevas formas de tributación que es lo que me interesa más. La reconstrucción de España depende más de la reforma de la tributación que de idear nuevos empleos a los tributado... soy uno de los españoles que están más pendientes del curso que tome la labor política de usted, de quien puede surgir la resurrección del hoy moribundo liberalismo español" ${ }^{23}$.

Se evidencia también que no sólo les une una profunda afinidad política sino que además se ha establecido entre ellos una buena relación de amistad y confianza que se evidencia en las cartas de recomendación de Unamuno para varios funcionarios de Hacienda y la solicitud de que el edificio del Colegio Viejo de San Bartolomé, en Salamanca, se destine a

22 Archivo Unamuno. Carta de Alba a Unamuno, 8-10-1916

${ }^{23}$ Archivo Alba. Carta de Unamuno a Alba, 14-1-1917. 
Instituto de Segunda Ensañanza y no sea incautado. Justas peticiones que son atendidas por Alba con todo afecto ${ }^{24}$.

En abril de 1918, cuando Alba ocupa la cartera de Instrucción Pública en el Gobierno Nacional presidido por Maura, Unamuno aprovecha la ocasión para que su amigo, ahora ministro, inquiera a Bergamin, que lo fue en 1914, a que justifique los motivos, hasta ahora ocultos, por los que le destituyó de su cargo de Rector de la Universidad de Salamanca. No ha olvidado don Miguel la afrenta y sigue reclamando una explicación a la despótica conducta, pues «en ningún caso es lícito - escribe a Alba- ni retirar la confianza ministerial, que es pública, ni proceder en nada contra ningún funcionario público, de la categoria que sea, sino por razones publicables y justificables en público. No se trata, pues, de nada personal ni individual mio... De mi sincera amistad con usted y de que estoy persuadisimo de cuan buena fe quiere usted buscarme una satisfacción, no cabe, puesto como ve el pleito es de principios" ${ }^{25}$. Muchos años tendrá que esperar, hasta mayo de 1931, para volver a ocupar el cargo de Rector en su querida Salamanca.

Como un recurso constante en su vida, Unamuno vuelve a su soledad y abandona, casi por completo, su actividad pública aunque no por ello renuncia a la crítica acerada de una politica mediocre que detesta. "He salido de la soledad en que continuamente vivo - dice en septiembre de 1922 en Valencia - para tener aqui, ante vosotros, una especie de conversación conmigo mismo... pero, volveré a embozarme en mis pensamientos, y volveré allá a afilar la pluma, y acaso, acaso a rumiar de un pasto amargo, de pensamiento, y a cocer en acibar una porción de hieles que a todas las personas nos están envenenando; nos está envenenando un sistema de gobierno de mentira y de coacción. En esto se pasa indudablemente muchas amarguras. Eso sólo lo saben los que horas y horas se encierran en su casa consigo mismo y saben lo que pasa" ${ }^{26}$. Solitario, pero con la compañía de sus amigos y, cómo no, de Alba, quien convirtiéndose en su cómplice le argumenta que "la soledad es el deleite de los exquisitos. iSéalo; pues, pero sabiendo que le acompaña el afecto y la admiración de las gentes! ${ }^{27}$.

\footnotetext{
${ }^{24}$ Archivo Alba. Cartas de Unamuno a Alba, 15-11-1916, 14-1-1917, 15-3-1917 y 24-3-1917. Archivo Unamuno. Cartas de Alba a Unamuno, 24-11-1916, 25-3-1917 y 31-3-1917.

25 Archivo Alba. Carta de Unamuno a Alba, 30-4-1918.

${ }^{26}$ Unamuno, M., "Discurso en la Casa de la Democracia de Valencia el 7-9-1922", publicado en El Puebio. Valencia, 8-9-1922.

${ }^{27}$ Archivo Unamuno. Carta de Alba a Unamuno, 10-2-1920.
} 


\section{EN EL EXILIO DURANTE LA DICTADURA}

El golpe de Estado y el nuevo régimen dictatorial impuesto por el general Primo de Rivera, en septiembre de 1923, contaron, en sus primeros meses, con la aceptación y la simpatía de gran parte de la sociedad española y de los partidos políticos y sus dirigentes más representativos. La primera reacción de Primo de Rivera hacia el Gobierno liberal derrocado fue verbalmente de fuerte dureza, descalificando su proceder y amenazando a sus miembros con posibles represalias. Sin embargo, a las primeras declaraciones no siguió una politica represiva; en realidad, la actitud del Dictador fue de extrema condescendencia con los antiguos políticos, llegando incluso, pasado cierto tiempo, a buscar su participación en el nuevo régimen.

La excepción de este proceder fue con la persona de Santiago Alba. Primo de Rivera descargó en el ex-ministro de Estado todos los supuestos vicios y responsabilidades del sistema parlamentario y de gobiernos anteriores. Urdió una campaña calumniosa que al final se volvió contra él, convirtiéndose en una de las claves de la posterior reacción anti-dictatorial, porque al demostrarse el escaso fundamento de sus actuaciones, se hizo evidente, en la "paternal» Dictadura española, uno de los más repulsivos achaques de los regimenes de excepción ${ }^{28}$.

A los pocos dias del Golpe, Primo de Rivera formuló una serie de acusaciones contra Alba, relacionadas casi todas ellas con la politica marroqui que desarrolló durante 1923, pero ante su falta de fundamento, el Dictador, obsesionado con perseguirle, recurrió al innoble procedimiento de elegir a un miembro de la Magistratura para procesar a don Santiago, utilizando para ello todo tipo de medios: delaciones, acusaciones falsas, etc. Ya en manos del Tribunal Supremo, el "caso Alba" se vio definitivamente resuelto el 19 de noviembre de 1926 con el sobreseimiento del proceso, no quedando la más minima duda sobre su inocencia y la falsedad de las acusaciones que sobre él vertió la Dictadura.

De los pocos intelectuales que inmediatamente se opusieron a la Dictadura, el de mayor relevancia, sin duda alguna, fue Unamuno. Para un temperamento tan rebelde e insometible como el suyo resultaba impensable estar mucho tiempo recluido en corregir sus versos. A escasos días del Golpe surgió la respuesta que, ante todo y sobre todo, consistió en

${ }^{28}$ Seco Serrano, C., "El cerco de la Monarquía. La ruptura de los partidos dinásticos con Alfonso XIII durante la Dictadura de Primo de Rivera", en Boletin de la RAH, tomo CLXXXIII, cuaderno II. Madrid, mayo-agosto, 1986, pág. 179. 
una apelación a la inteligencia, al ejercicio de la misma y a la clase intelectual que representaba ${ }^{29}$. Fue también Unamuno uno de los pocos que defendió públicamente a Alba de los ataques del Directorio, en un articulo titulado «No hay que calumniar» denunció la campaña promovida por Primo de Rivera, afirmando rotundamente que caunque no fuimos ni somos partidarios del señor Alba; le combatimos cuando le creiamos equivocado, pero jamás se nos ocurriría inculparle de culpas que sabemos que no cometió y jamás de que persiguiese fuera de la ley a los que le escarnecían» ${ }^{30}$.

Alba, desde el exilio en Francia, escribe a Unamuno una extensa misiva en la que agradece su defensa, le explica la persecución a que se ve sometido y la censura de prensa que el General ejerce impidiéndole responder públicamente a sus acusaciones:

"Mi querido y admirado amigo: Con intensa y cordial emoción acabo de leer su hermoso articulo. Me apresuro a escribir a usted no para enviarle, aún siendo ella obligada, la expresión de una gratitud que habrá de imaginar, desde luego, sino para confirmar y fortalecer en usted, mediante la exposición de unos cuantos datos, el noble anhelo de reparadora justicia que vibra, en medio de la cobardia general... conmigo se está cometiendo por estos flamantes regeneradores la más vil, la más odiosa de las inquinidades.

Ligera y brutalmente permitiose al General sublevado, insultarme y calumniarme en su manifiesto al pais.

Para completar su juicio, acompaño a usted copia de la carta que hube de dirigir a Su Majestad el Rey... Vea usted en cuanto queda escrito, un adecuado homenaje a la elevación de pensamiento y al sentido liberal y humano de su artículo. Haga lo que quiera y pueda en el asunto. Le reitero mi gratitud de por vida" ${ }^{31}$.

Alba, como es natural, desde el momento en que comenzó la persecución sobre su persona, quiso defenderse de las falsas acusaciones del Dictador. Primero desde las páginas del $A B C$ y luego desde el diario francés $L$ 'écho de Paris, replicó a las imputaciones de los golpistas. Rápidamente, Primo de Rivera aplicó una férrea censura de prensa sobre todo lo que se refiriera a Alba, asi es que éste, privado de la pública defensa, desde Bruselas y con la intermediación del Embajador Marqués de Villa-

${ }^{29}$ Garcia Queipo de Llano, G., Los intelectuales y la dictadura de primo de Rivera. Alianza Editorial, 1988, pág. 20.

${ }^{30}$ El Liberal, 25-10-1923.

${ }^{31}$ Archivo Unamuno. Carta de Alba a Unamuno, 28-10-1923. 
lobar, escribió el 1 de octubre de 1923 a Alfonso XIII en demanda de justicia ${ }^{32}$.

Durante casi todo el año 1924 la oposición a los planes del Directorio fue extremadamente débil. Pero, a pesar de existir un conformismo generalizado en la opinión pública y que los antiguos partidos, con excepción del socialista, estaban prácticamente deshechos, la contestación a la Dictadura, aunque frágil y escasa, nunca dejó de existir. Los primeros en mostrar su oposición fueron los intelectuales. Rompió el fuego el insobornable Unamuno y pronto le siguieron Rodrigo Soriano y los miembros de la Junta Directiva del Ateneo madrileño. Las sanciones vinieron de inmediato y el Gobierno decidió clausurar el Ateneo y destituyó de su puesto y cátedra a Miguel de Unamuno, desterrándole el 20 de febrero de 1924, junto a Rodrigo Soriano, a Fuenteventura. La deportación del antiguo Rector supuso el comienzo de un progresivo apartamiento de los intelectuales del Régimen, declarándose cada vez más incompatibles con la persona y métodos del Dictador.

En cuanto Alba conoce el desafuero cometido contra Unamuno le escribe una cariñosa carta en la que además de mostrarle «la impresión de ira y de asco" que le produjo la noticia de su deportación y de condenar "la estulticia y el espíritu facineroso de los tiranuelos deshonran a España", le brinda toda su ayuda, tanto a él, a través de sus antiguos compañeros albistas en Canarias, como a su familia en términos verdaderamente fraternales: "sé que su mujer -le escribe Alba-y sus hijos han recibido ofrecimientos de algunos españoles, que todavia conservan el sentimiento de una doble solidaridad, pero si el alejamiento de usted se prolonga, o cualquiera otra causa impide que utilice aquellos, conste que yo estoy dispuesto a considerarles como una prolongación de mi propia familia. $Y$, aunque los tiranuelos dominantes me han embargado todos mis bienes y hasta las cuentas corrientes de los Bancos, como vive mi madre y aún cuento con algunos amigos adinerados, todos correríamos la misma suerte" ${ }^{33}$.

Desde Puerto Labores de Fuerteventura, Unamuno se pone en contacto con Alba, sintiéndose profundamente unido a él en la persecución que ambos sufren. A pesar de lo ocurrido, Unamuno exhibe su esperanza y su fortaleza, rechazando todo lo que sea pedir merced o indulto y cada vez más convenido de la necesidad de luchar contra la Dictadura. "Yo, como usted, -le escribe a Alba - no pienso volver a España mientras no

\footnotetext{
${ }^{32} A B C, 23-9-1923$. L'Echo de Paris, 21-9-1923, articulo titulado «M. Alba ancien ministre, nous ecrit, pour se justifier". Archivo Alba. Carta de Alba a Alfonso XIII, 1-10-1923.

${ }^{33}$ Archivo Unamuno. Carta de Alba a Unamuno, 14-4-1924.
} 
tengan que huir de ella o caer presos esos desgraciados, sin más que serrín en la mollera y pus en el corazón. Mientras el Anido - a quién hace instigador y verdadero culpable del procesamiento de Alba- siga suelto y desbocado, sin aperos ni bozal, no está segura alli la vida de ningún ciudadano honrado y viril» ${ }^{34}$. En julio de 1924, Unamuno huye a Fuerteventura, se traslada a Las Palmas y de alli a Cherbourg y a Paris, odisea que cuenta con todo detalle a su amigo Alba:

"A mi llegada a Las Palmas recibo con alegria su grata carta, que me hace recordar al antiguo amigo de los felices dias de la juventud y al perseguido de hoy, doblemente simpático para mi... Desde hace tres meses largos teniamos preparada la fuga... (mis amigos) fletaron un barco velero que hubimos de esperar más de cuarenta noches en una roca solitaria de la costa de Puerto de Cabras. ¿Cómo explicarle nuestro pequeño drama, en las interminable noches, temiendo ser capturados pues la vigilancia era muy estrecha y dos parejas de la guardia civil vigilaban nuestras habitaciones toda la noche? Al fin vencimos. El buque, perseguido, tuvo que parar en Marruecos pero llegó por ingeniosos medios que despistaron a nuestros carceleros. Embarcamos ya muy cerrada la noche y con gran temporal, en una playa a tres horas de Puerto Cabras. Ya pasamos en el mar cinco dias enmedio de un temporal que puso en peligro nuestra embarcación. Llegados por fin a Las Palmas... Embarcamos el 21 en un barco holandés que va a Cherbourg y de esta ciudad a Paris. ¡Qué alegria verle, contarle nuestros sufrimientos, reconfortar su ánimo!» ${ }^{35}$.

Ya en Paris, Unamuno visita a Alba estableciendose entre ellos una profunda relación. Buena prueba de ello es la cariñosa carta que Unamuno le escribe en mayo de 1925, que comienza diciendo: «Mi querido amigo, compañero (com-panio quiere decir que come del mismo pan, el nuestro del destierro) y colega (col-leccionados juntos)». Continúa su misiva censurando la política francesa en Marruecos y despotricando de Primo de Rivera, de quién afirma que «sigue yendo de pueblo en pueblo en busca de Virgenes de palo, imágenes o fetiches, creyéndose sin duda, que la venerada Madre del Hijo Eterno, la que nos llenó de luz y ternura la infancia, es una Celestina de la Unión Patriótica. ¡Sacrilegio! ${ }^{36}$.

A los dos años (1924-1925) de esperanza y fuerza incontenible de Unamuno en su lucha contra la Dictadura, le sigue un período de soledad,

\footnotetext{
${ }^{34}$ Archivo Alba. Cartas de Unamuno a Alba, 25-4-1924 y 5-5-1924.

35 Archivo Alba. Carta de Unamuno a Alba, 12-7-1924.

${ }^{36}$ Archivo Alba. Carta de Unamuno a Alba, 7-5-1925.
} 
pesimismo y falta de interés por la politica, que dedica intensamente a escribir. Desde Hendaya le describe a Alba su estado de ánimo y cómo transcurren sus dias: "Trabajo mucho; he reanudado mis colaboraciones en América... Visito la mar y la montaña y con impresiones de ellas estoy haciendo un libro que titularé: Hendaya. Nada de politica; poesia en prosa y verso-descripciones, filosofía, religión y hasta mistica. Sigo descubriendo la mar... Cuando me pesa demasiado nuestra España me voy a la playa de Ondarraitz a oir las olas que me traen mil siglos de historia... Han empezado a publicar mis obras completas en alemán; van cuatro volúmenes. Voy a firmar contrato con una casa holandesa y otra sueca... Vaya un abrazo de su amigo y co-víctima ${ }^{37}$.

En marzo de 1927 Unamuno participa en la publicación de Hojas Libres, revista dirigida por Eduardo Ortega y Gasset que servia como plataforma politica de los opositores a la Dictadura exiliados en Francia. Mientras el grupo de intelectuales reunidos en torno a esta publicación trasladaban su crítica furibunda de Primo de Rivera a la institución monárquica y a la persona del Rey, Alba no tradujo su apartamiento de la Corona en hostilidad o rencor, ni abrazó posiciones radicales y antimonárquicas, negando su participación a los actos y declaraciones de los exiliados en Francia. Cuando en agosto de 1925 este grupo celebró un mitin en Hendaya, en nombre de la Liga de los Derechos del hombre, Alba intencionadamente no asistió; quiso dejar claro con ello que no estaba alineado con la politica radical de sus organizadores y no era cómplice de la campaña que contra Alfonso XIII habian desatado. Esto no fue óbice para que Unamuno, que intervino en dicho mitin, dirigiera su discurso en conseguir el apoyo de Sánchez Guerra y de Alba, sin los cuales no podia estar completo el movimiento contra la Dictadura ${ }^{38}$.

El fin de Primo de Rivera tuvo lugar cuando ante el anunciado alzamiento de Cádiz, que dirigia el general Goded, el 28 de enero de 1930, todos los mandos del Ejército y la Marina le retiraron su apoyo, y el Rey encargó al general Berenguer la constitución de un nuevo Gobierno. Inmediatamente Unamuno regresa a España y el nuevo Gabinete decide devolverle su cátedra, injustamente arrebatada por el Dictador. Como no, Alba enseguida le escribe alegrándose del fin de su exilio y de su vuelta a la cátedra, «obra de reparación - le dice- que se imponia al acabar la vergonzosa e inmunda Dictadura» y recordándole que «no olvidará jamás que el primer choque de usted con el tiranuelo fue aquel hermoso y noble articulo en que me defendia de sus groseras e inicuas invencio-

${ }^{37}$ Arhivo Alba. Carta de Unamuno a Alba, 15-12-1925.

${ }^{38}$ Archivo Natalio Rivas. Leg. 11-8916, diario, 29-9-1925. 
nes" ${ }^{39}$. Alba, a diferencia de Unamuno, no tiene prisa por volver a Madrid, sobre todo, cuando todavía no existe un régimen de garantias que le permita actuar con plena libertad de crítica y de opinión y su vuelta podria ser mal interpretada como apoyo a la Monarquía.

Desde su añorada Salamanca, Unamuno anima a Alba a volver a su patria y le muestra, una vez más, su profunda admiración: «En alguna ocasión, -le dice- alguno de esos desdichados que no sienten la politica si no como oficio de granjería me ha dicho, ¿pero es usted albista?. $Y$ yo he respondido que soy un hombre que no puede soportar la injusticia, sea quien fuere víctima de ella, pero además, soy un buen amigo de Alba a quien creo conocer algo. Y como creo conocerle, no ha de ofenderle dejándome llamar albista pues a mí no me ofenderia que mis amigos se llamaran unamunistas" ${ }^{40}$.

He querido resaltar en este articulo como Unamuno y Alba, a pesar de sus notables diferencias, mantienen durante más de 30 años un fuerte vinculo de amistad e importantes coincidencias ideológicas, puestas de manifiesto en su vocación regeneradora de la vida politica, en su afán democritazador del caduco sistema de la Restauración y, sobre todo, en la defensa a ultranza de la libertad, tantas veces quebrantada durante estos años. Dos inconformistas perseguidos por el Poder y muchas veces incomprendidos por la propia sociedad española a quien querian transformar.

${ }^{39}$ Archivo Unamuno. Carta de Alba a Unamuno, 7-2-1930.

${ }^{40}$ Archivo Alba. Carta de Unamuno a Alba, 20-2-1930. 